\title{
Inflammation-Induced Lethargy Is Mediated by Suppression of Orexin Neuron Activity
}

\author{
Aaron J. Grossberg, ${ }^{1,2}$ XinXia Zhu, ${ }^{2}$ Gina M. Leinninger, ${ }^{3}$ Peter R. Levasseur, ${ }^{2}$ Theodore P. Braun, ${ }^{2}$ Martin G. Myers Jr, ${ }^{3,4}$ \\ and Daniel L. Marks ${ }^{2}$ \\ ${ }^{1}$ Neuroscience Graduate Program, and 2Papé Family Pediatric Research Institute, Department of Pediatrics, Oregon Health \& Science University, Portland, \\ Oregon 97239, and ${ }^{3}$ Division of Metabolism, Endocrinology, and Diabetes, Department of Internal Medicine, and ${ }^{4}$ Department of Molecular and Integrative \\ Physiology, University of Michigan, Ann Arbor, Michigan 48109
}

In response to illness, animals subvert normal homeostasis and divert their energy utilization to fight infection. An important and unexplored feature of this response is the suppression of physical activity and foraging behavior in the setting of negative energy balance. Inflammatory signaling in the hypothalamus mediates the febrile and anorectic responses to disease, but the mechanism by which locomotor activity (LMA) is suppressed has not been described. Lateral hypothalamic orexin (0x) neurons link energy status with LMA, and deficiencies in Ox signaling lead to hypoactivity and hypophagia. In the present work, we examine the effect of endotoxin-induced inflammation on Ox neuron biology and LMA in rats. Our results demonstrate a vital role for diminished 0x signaling in mediating inflammation-induced lethargy. This work defines a specific population of inflammation-sensitive, arousal-associated Ox neurons and identifies a proximal neural target for inflammatory signaling to $0 x$ neurons, while eliminating several others.

\section{Introduction}

The maintenance of energy homeostasis is crucial to ensure long-term survival. Normally, energy intake and expenditure are precisely controlled, stabilizing body weight over an animal's lifetime. Because infectious illness is an acute threat to life, systems have evolved that sacrifice energy homeostasis to provide the greatest chance of survival. Indeed, all of the behaviors and metabolic changes typical of sickness, including fever, anorexia, and lethargy, are linked directly to a highly organized strategy of reassigning biological and physiological priorities to fight infection (Dantzer, 2001).

During the course of a disease, locally produced inflammatory signals alter the activity of hypothalamic homeostatic systems. For example, fever is caused by prostaglandin $\mathrm{E}_{2}$-mediated activation of cold-sensitive neurons in the preoptic area (Gordon and Heath, 1980), while inflammatory cytokines regulate proopiomelanocortin (POMC)-expressing and agouti-related peptide (AgRP)-expressing neurons in the arcuate nucleus (Scarlett et al., 2007, 2008), leading to anorexia (Grossberg et al., 2010) and increased thermogenesis (Arruda et al., 2010). Sickness behavior is characterized by the suppression of normal locomotor responses to circadian, metabolic, and emotional stimuli, thereby minimizing energy expenditure. These locomotor deficits are not

\footnotetext{
Received May 6, 2011; revised June 13, 2011; accepted June 28, 2011.

Author contributions: A.J.G., T.P.B., and D.L.M. designed research; A.J.G., X.Z., G.M.L., and P.R.L. performed research; G.M.L. and M.G.M. contributed unpublished reagents/analytic tools; A.J.G. and D.L.M. analyzed data; A.J.G. and D.L.M. wrote the paper.

The authors declare no competing financial interests.

Correspondence should be addressed to Dr. Daniel L. Marks, Papé Family Pediatric Research Institute, Department of Pediatrics, Oregon Health \& Science University, Mail Code L-481, 3181 SW Sam Jackson Park Road, Portland, OR 97239. E-mail:marksd@ohsu.edu.

DOI:10.1523/JNEUROSCI.2311-11.2011

Copyright $\odot 2011$ the authors $\quad 0270-6474 / 11 / 3111376-11 \$ 15.00 / 0$
}

improved by restoring food intake in immune-challenged animals (Marks et al., 2001), suggesting that locomotor activity (LMA) is independently regulated during the course of a disease. The inflammation-sensitive population of neurons that mediates the lethargic response to sickness has not yet been identified, however.

One set of neurons implicated in the allostatic control of arousal and physical activity is the orexin (Ox; hypocretin)expressing neurons of the perifornical lateral hypothalamic area (LHA) (Trivedi et al., 1998). Ox neurons are activated during waking, stress, exposure to novel environments, and undernutrition (Sakurai, 2007). Ox neurons are also responsive to circulating signals of energy status and mediate the increase in foraging behavior exhibited by food-restricted (FR) animals (Yamanaka et al., 2003; Mieda et al., 2004; Sakurai, 2007). Ox neurons are linked to other motivated behaviors as well, including drugseeking and sexual behavior (Harris and Aston-Jones, 2006). Together, this work demonstrates that orexins serve as a crucial intermediate step that manipulates arousal in response to metabolic needs, stress, and reward-oriented stimuli.

Several lines of evidence suggest that Ox neurons mediate inflammation-induced lethargy. First, Ox knock-out mice exhibit marked hypophagia, hypolocomotion, hypersomnolence, and an inability to adapt to restricted feeding, a phenotype resembling sickness behavior (Chemelli et al., 1999; Mieda et al., 2004). Second, a localized reduction in cFos immunoreactivity (IR) in the LHA has been observed following inflammatory insults, indicating reduced neuron activity in this region (Becskei et al., 2008; Gaykema and Goehler, 2009). Third, LHA glucosesensitive neurons have reduced electrical activity in the presence of interleukin-1 $\beta$ (IL-1 $\beta$ ) or tumor necrosis factor- $\alpha$ (TNF- $\alpha$ ) (Plata-Salamán et al., 1988). In the present work, we use lipopoly- 
saccharide (LPS)- and tumor-induced models of inflammation to investigate whether suppression of Ox signaling mediates the lethargic response to sickness. We also evaluate the proximal neural input by which inflammation inhibits $\mathrm{Ox}$ neurons, and investigate the connection between the central melanocortin and orexin systems.

\section{Materials and Methods}

Animals and surgical procedures. Male Sprague Dawley (250-450 g; Charles River Laboratories) or F344/NTacfBR rats (200-250 g; Taconic Farms) and neurotensin (Nts)-cre/GFP mice (Leinninger et al., 2011) were maintained on a normal $12 \mathrm{~h}$ light/dark period with lights on from 6:00 A.M. to 6:00 P.M., corresponding to zeitgeber time (ZT) 0-12, at $22-24^{\circ} \mathrm{C}$ with ad libitum access to food (rodent diet 5001, Purina Mills) and water, unless otherwise noted. Experiments were conducted in accordance with the National Institutes of Health Guide for the Care and Use of Laboratory Animals and was approved by the Animal Care and Use Committee of Oregon Health and Science University or the University of Michigan. The generation of the Nts-cre/GFP mice is detailed by (Leinninger et al., 2011).

Locomotor activity and temperature. Voluntary home-cage LMA and brown adipose tissue (BAT) temperature were measured using implantable telemetric transponders (MiniMitter). Animals were anesthetized using $2 \%$ isoflurane, a small midline incision was made just anterior to the BAT, and transponders were implanted beneath the BAT, with care taken to leave innervation unperturbed. For rats receiving intracerebroventricular injections, transponders were implanted during the lateral ventricle cannulation surgery. Rats were individually housed and allowed to acclimate for at least $5 \mathrm{~d}$ before temperature and net movement on $x$-, $y$-, and $z$-axes was recorded in 1 min intervals (Vital View, MiniMitter).

Implantation of lateral ventricle cannulae. Sprague Dawley or F344/ NTacfBR rats were anesthetized with $2 \%$ isoflurane and placed in a stereotaxic apparatus (David Kopf Instruments). A sterile guide cannula with obturator stylet (Plastics One) was stereotaxically implanted into the lateral ventricle. The coordinates used were as follows: $1.0 \mathrm{~mm}$ posterior to bregma; $1.5 \mathrm{~mm}$ lateral to midline; and $4.1 \mathrm{~mm}$ below the surface of the skull (Paxinos and Watson, 1998). The cannula was fixed in place with dental cement. The animals were individually housed after surgery for a minimum of 1 week and were handled daily for at least $3 \mathrm{~d}$ before each treatment.

Dark-phase LPS injections. For evening experiments, on the day of the experiment at ZT 10.5, individually housed animals received intraperitoneal injections of LPS (Sigma-Aldrich) $(250 \mu \mathrm{g} / \mathrm{kg})$ dissolved in $0.5 \%$ low-endotoxin BSA (Equitech-Bio) in $0.9 \%$ saline, or $0.5 \%$ BSA in $0.9 \%$ saline alone, and were placed in their home cage without food. Behavioral studies were conducted with a crossover design, with activity and temperature monitored throughout the evening. The following morning at ZT 23.5, rats were anesthetized with $2 \%$ isoflurane, and CSF was collected by percutaneous cisterna magna puncture (Desarnaud et al., 2004). Protease inhibitor cocktail (Roche Diagnostics) was added to the $\mathrm{CSF}$ before snap freezing on dry ice and storage at $-80^{\circ} \mathrm{C}$. Following $5 \mathrm{~d}$ of recovery, treatment groups were switched and the experiment was repeated. For histology experiments, rats or mice were killed at ZT 13.5 and processed for immunohistochemistry (IHC), as described below. Experiments were performed on serial days to minimize variation in the time of death between animals.

Central OxA replacement experiments. For the acute OxA replacement experiments, male Sprague Dawley rats were implanted with lateral ventricle cannulae and telemetric transponders. After $5 \mathrm{~d}$ of recovery and handling, LPS was administered at ZT 10.5 and food was removed, as described above, followed by intracerebroventricular injection of OxA ( 1 $\mu \mathrm{g}$; California Peptide Research) dissolved in aCSF or aCSF alone. In the lethargy prevention experiment (experiment 1 ), intracerebroventricular injections were conducted at ZT 11.5; in the lethargy reversal experiment (experiment 2), intracerebroventricular injections were performed at ZT 15. Following injection, rats were returned to their cages, and activity and temperature were measured. For the subchronic Ox replacement experiment (experiment 3), rats were implanted with Alzet intracerebroven- tricular brain infusion kits connected to $3 \mathrm{~d}$ osmotic minipumps $(1 \mu \mathrm{l} / \mathrm{h}$; model 1003D, Durect) on the day before the experiment using the above coordinates for lateral ventricle cannulation. Pumps were filled with OxA dissolved in aCSF $(3 \mu \mathrm{g} / \mu \mathrm{l})$ or aCSF. During pump assembly and priming, the catheters connecting the minipumps to the cannulae were filled with saline with a small bubble to separate the saline from the drug. These catheters were measured such that the drug began delivery into the brain $\sim 1-2 \mathrm{~h}$ before onset of the dark phase on the experimental day. During minipump implantation, the distance from the bubble to the cannula was confirmed to ensure appropriate treatment start time. On the day of the experiment at ZT 10.5, rats were injected intraperitoneally with LPS or vehicle (veh), as described above, except that food was weighed and returned to the cage. Activity, temperature, and food intake were measured during the subsequent $24 \mathrm{~h}$ period.

Central anti-inflammatory treatments. Sprague Dawley rats were implanted with lateral ventricle cannulae and subcutaneous telemetric transponders, and were allowed to recover for $5 \mathrm{~d}$ before the beginning of these experiments. Peripheral LPS treatments were performed as described above with slight modifications. In the central IL-1 blockade experiment, rats were cotreated with intracerebroventricular IL-1ra (4 $\mu \mathrm{g})$ dissolved in aCSF plus $0.5 \%$ BSA versus vehicle and intraperitoneal LPS $(250 \mu \mathrm{g} / \mathrm{kg})$ versus vehicle injection at ZT 10.5 (4:30 P.M.). Food was weighed and returned to the cages as a positive control for central drug action. Food intake, body weight, temperature, and activity were recorded. Following $5 \mathrm{~d}$ of recovery, rats were crossed over such that all animals received a different intraperitoneal and intracerebroventricular treatment and the experiment was repeated. For nonspecific systemic prostaglandin (PG) blockade, rats were pretreated with intraperitoneal indomethacin (indo; $4 \mathrm{mg} / \mathrm{kg}$ ) dissolved in DMSO versus vehicle at ZT 10 (4:00 P.M.). Rats were subsequently treated with intraperitoneal LPS $(250 \mu \mathrm{g} / \mathrm{kg})$ versus vehicle injection at ZT 10.5 (4:30 P.M.). For central cyclo-oxygenase (COX)-2 inhibition, rats were cotreated with intracerebroventricular NS-398 (5 $\mu \mathrm{g})$ dissolved in 50\% DMSO/50\% $0.01 \mathrm{M} \mathrm{PBS}$ versus vehicle and intraperitoneal LPS $(250 \mu \mathrm{g} / \mathrm{kg})$ versus vehicle injection at ZT 10.5 (4:30 P.M.). In both PG blockade experiments, rats had ad libitum access to food and water, and data were collected as described in the IL-1ra experiment. Body temperature was monitored as a positive control for PG inhibition.

Central opioid blockade. Sprague Dawley rats were implanted with lateral ventricle cannulae and subcutaneous telemetric transponders, and were allowed to recover for $5 \mathrm{~d}$ before the beginning of the experiment. Peripheral LPS treatments were performed as described above with slight modifications. Rats were cotreated with intracerebroventricular naltrexone (NTX; $5 \mu \mathrm{g}$ ) dissolved in normal saline versus vehicle and intraperitoneal LPS $(250 \mu \mathrm{g} / \mathrm{kg})$ versus vehicle injection at ZT 10.5 (4:30 P.M.). Food intake, body weight, temperature, and activity were recorded. Following $5 \mathrm{~d}$ of recovery, rats were crossed over such that all animals received a different intraperitoneal and intracerebroventricular treatment and the experiment was repeated.

$R N A$ preparation and quantitative $R T-P C R$ in FR rats. Male Sprague Dawley rats were allowed ad libitum access to food or FR for $8 \mathrm{~d}$, as described in the main text. On experiment day, rats were injected with LPS $(250 \mu \mathrm{g} / \mathrm{kg}$, i.p.) versus vehicle at 7:30 A.M. (ZT 1.5). One hour later (ZT 2.5), the animals were deeply anesthetized using sodium pentobarbital ( $65 \mathrm{mg} / \mathrm{kg})$, the thoracic cavity was opened, and blood was collected by cardiac puncture of the right ventricle. Blood was stored on ice until the end of the experiment, then plasma was isolated and frozen at $-80^{\circ} \mathrm{C}$. Rats were then perfused with RNase-free DEPC $0.01 \mathrm{~m}$ PBS plus heparin sodium $(15,000 \mathrm{U} / \mathrm{L})$ to flush the vasculature in the hypothalamus. Hypothalamic blocks with median eminence attached were isolated, preserved in RNAlater solution (Ambion), and stored at $4^{\circ} \mathrm{C}$ overnight. RNA was extracted the next day and used for quantitative RT-PCR analysis, as described previously (Scarlett et al., 2008). cDNA was synthesized, and RT-PCR reactions were run using prevalidated TaqMan master mix and primer-probes (Applied Biosystems). Statistical analysis using twoway ANOVA followed by post hoc analysis using Bonferroni's corrected $t$ test performed on delta cycle threshold $\left(\mathrm{dC}_{t}\right)$ values. Raw $\mathrm{C}_{t}$ values from $18 \mathrm{~S}$ ribosomal subunit endogenous controls were compared between groups to validate observed changes in target genes. 
Plasma IL-6 ELISA. Plasma was collected as described above. IL-6 ELISA (R\&D Systems) was performed according to the manufacturer's instructions. All samples were run at 1:2 dilution as well as 1:200 dilution to ensure that the concentration was within the dynamic range of the assay.

In situ hybridization histochemistry. Fresh frozen brains were collected and processed for in situ hybridization as previously described (Scarlett et al., 2007), with the following modifications. Hypothalamic coronal sections $(30 \mu \mathrm{m})$ were collected in a 1:6 series from the diagonal band of Broca ( $0.50 \mathrm{~mm}$ from bregma) caudally through the mammillary bodies (5.00 $\mathrm{mm}$ from bregma). Antisense ${ }^{33} \mathrm{P}$-labeled rat preproorexin $(\mathrm{Hcrt})$ riboprobe (corresponding to bases 18-420 of rat Hcrt; GenBank accession number NM_013179) $(0.1 \mathrm{pmol} / \mathrm{ml})$ was denatured, dissolved in hybridization buffer along with tRNA $(1.7 \mathrm{mg} / \mathrm{ml})$, and applied to slides. Controls used to establish the specificity of the Hcrt riboprobe included slides incubated with an equivalent concentration of radiolabeled sense Hcrt riboprobe or radiolabeled antisense probe in the presence of excess $(1000 \times)$ unlabeled antisense probes. Slides were covered with glass coverslips, placed in a humid chamber, and incubated overnight at $55^{\circ} \mathrm{C}$. The following day, slides were treated with RNase A and washed under conditions of increasing stringency. Slides were dipped in 100\% ethanol, air dried, and then dipped in NTB-2 liquid emulsion (Eastman Kodak). Slides were developed $6 \mathrm{~d}$ later and coverslipped. Blinded counts of the number of silver grain clusters (corresponding to radiolabeled Hcrt mRNA) in each hypothalamic nucleus (user defined) as well as the number of silver grains in each cell were made using Grains 2.0.b software (University of Washington, Seattle, WA).

Double-label in situ hybridization was used for simultaneous visualization of Hcrt mRNA with IL-1RI, TNF-R, LIF-R, I $\kappa \mathrm{B} \alpha, \mathrm{MC} 3-\mathrm{R}$, and MC4-R in the rat brain $(n=3)$ was performed as previously reported (Scarlett et al., 2007), with slight modifications. Tissue was prepared as described above. Antisense digoxigenin-labeled rat Hcrt riboprobe and antisense ${ }^{33} \mathrm{P}$-labeled IL-1RI (bases 207-930 of rat Il1r1; GenBank accession number M95578) (0.2 pmol/ml), I $\kappa \mathrm{B} \alpha$ (bases 112-922 of rat Nfbia; GenBank accession number NM_001105720) (0.1pmol/ml), TNF-R (bases 63-1129 of rat Tnfrsf1a; GenBank accession number NM_013091) (0.2 pmol/ml), LIF-R (bases 785-1645 of rat Lifr; GenBank accession number NM_031048) (0.2 pmol/ml), MC3-R (bases 90-486 of rat Mc3r; GenBank accession number NM_001025270) $(0.3 \mathrm{pmol} / \mathrm{ml})$, or MC4-R (bases 557-1006 of rat Mc4r; GenBank accession number NM_013099) $(0.3 \mathrm{pmol} / \mathrm{ml})$. Coexpression of radiolabeled and digoxigenin-labeled mRNA was assessed using criteria previously described (Cunningham et al., 2002). Signal-to-background ratios for individual cells were calculated; an individual cell was considered to be double labeled if it had a signal-to-background ratio of $\geq 2.5$. For each animal, the amount of double labeling was calculated as a percentage of the total number of Hcrt-expressing cells and then averaged across animals to produce the mean \pm SEM.

Perfusion and IHC. For histology experiments, rats or mice were deeply anesthetized using sodium pentobarbital $(65 \mathrm{mg} / \mathrm{kg})$ and were killed by transcardial perfusion fixation with $150 \mathrm{ml}$ (rats) or $15 \mathrm{ml}$ (mice) ice-cold $0.01 \mathrm{M}$ PBS plus heparin sodium (15,000 U/L) followed by $200 \mathrm{ml}$ (rats) or $25 \mathrm{ml}$ (mice) $4 \%$ paraformaldehyde (PFA) in $0.01 \mathrm{M} \mathrm{PBS}$. Brains were post-fixed in $4 \%$ PFA overnight at $4^{\circ} \mathrm{C}$ and cryoprotected in $20 \%$ sucrose for $24 \mathrm{~h}$ at $4^{\circ} \mathrm{C}$ before being stored at $-80^{\circ} \mathrm{C}$ until used for IHC. Freefloating sections were cut at $30 \mu \mathrm{m}$ from perfused brains using a sliding microtome (model SM2000R, Leica Microsystems). Three (rats) or four (mice) sets of sections were generated from the hypothalamus of each brain. Hypothalamic sections were collected from the division of the optic chiasm (rats, $2.0 \mathrm{~mm}$ from bregma; mice, $1.0 \mathrm{~mm}$ from bregma) caudally through the mammillary bodies (rats, $5.00 \mathrm{~mm}$ from bregma; mice, $3.0 \mathrm{~mm}$ from bregma). The sections were incubated for $1 \mathrm{~h}$ at room temperature in blocking reagent $(5 \%$ normal donkey serum in $0.01 \mathrm{M}$ PBS and $0.1 \%$ Triton X-100). After the initial blocking step, the sections were incubated in rabbit anti-c-Fos antibody (PC38, EMD Biosciences) diluted 1:50,000, rabbit anti-cFos antibody (SC-52, Santa Cruz Biotechnology) diluted 1:25,000, and goat anti-OxA (SC-8070, Santa Cruz Biotechnology) diluted 1:1500 in blocking reagent for $72 \mathrm{~h}$ at $4^{\circ} \mathrm{C}$, followed by incubation in donkey anti-rabbit Alexa 594 (1:500; Invitrogen) and donkey anti-goat Alexa 488 (1:500; Invitrogen) for $2 \mathrm{~h}$ at room temperature. Triple-IF histochemistry was performed as described above with the following modifications. Nes-cre/GFP sections were incubated in blocking reagent as described above, then washed and incubated in the anti-cFos and anti-OxA antisera as well as chicken anti-GFP (Abcam), diluted 1:1000 for $72 \mathrm{~h}$ at $4^{\circ} \mathrm{C}$. Sections were then incubated in donkey anti-rabbit Alexa 594, donkey anti-chicken-FITC (Jackson Immunoresearch), and donkey anti-goat-DyLight 649 (Jackson Immunoresearch) for $2 \mathrm{~h}$ at room temperature. Between each stage, the sections were washed thoroughly with $0.01 \mathrm{M}$ PBS. Incubating the sections in the absence of primary antisera was used to ensure specificity of the secondary antibodies. Sections were mounted onto gelatin-coated slides, coverslipped using Vectashield mounting media (Vector Laboratories), and viewed under a fluorescence microscope (model 4000 DM, Leica Microsystems; or model LSM710, Carl Zeiss).

Peripheral LPS and central IL-1 $\beta$ injections in food-entrained rats. Sprague Dawley rats were implanted with lateral ventricle cannulae and subcutaneous telemetric transponders, and were allowed to recover for $5 \mathrm{~d}$ before the beginning of food entrainment. FR rats were individually housed, handled, and allowed access to food from ZT 4 to ZT 6 each day for $8 \mathrm{~d}$. Food intake, body weight, activity, and temperature were recorded daily. On day 9 , rats were injected intraperitoneally with LPS (250 $\mu \mathrm{g} / \mathrm{kg}$ ) or veh (LPS experiments), or were injected intracerebroventricular with IL-1 $\beta$ (100 ng; R\&D Systems) dissolved in aCSF plus $0.5 \%$ BSA or veh (IL-1 $\beta$ experiments) at ZT 1.5. In the behavioral studies, all animals then received intracerebroventricular injections of OxA $(1 \mu \mathrm{g})$ or aCSF at ZT 3. Food was placed in the cages from ZT 4 to ZT 6, and food intake, body weight, and activity were recorded. Food-anticipatory activity (FAA) was measured during the $60 \mathrm{~min}$ preceding food presentation. For histology studies, rats were killed at ZT 3.5 by transcardial perfusion fixation, as described below. Experiments were performed on serial days to minimize variation in the time of treatment and death between animals.

Tumor implantation. Male F344/NTacfBR rats were individually housed, and divided into the following four age- and weight-matched groups: sham-operated controls treated with aCSF; tumor-bearing rats treated with aCSF; tumor-bearing rats treated with AgRP; and shamoperated rats that were pair fed with the tumor-bearing/aCSF group. Seven days before tumor implantation, animals had lateral ventricle cannulae and biotelemetry devices implanted in a single surgery. On day 0 , the animals were anesthetized with $2 \%$ isoflurane, and fresh tumor tissue $(0.2-0.3 \mathrm{~g})$ from a rat donor was implanted subcutaneously into the flank of the rat, as previously described (Scarlett et al., 2008). The tumor is a methylcholanthrene-induced sarcoma that does not metastasize, and induces anorexia, cachexia, and lethargy (Smith et al., 1993). Beginning on day 10 after surgery, rats received $5 \mu$ intracerebroventricular injections of aCSF or AgRP ( $1 \mathrm{nmol})$ daily at ZT 10 . On day 13 after tumor implantation, tumor growth had fallen within the predetermined endpoints of the study, according to the Oregon Health \& Science University Institutional Animal Care and Use Committee Policy on Tumor Burden, and the animals were killed. The brains were immediately removed and frozen on dry ice. Brains were stored at $-80^{\circ} \mathrm{C}$ until in situ hybridization analysis.

OxA radioimmunoassay. OxA concentration was measured in rat CSF samples, which were collected as described above, using a commercially available radioimmunoassay (RIA) kit (Phoenix Pharmaceuticals). RIA was performed in duplicate on $25 \mu \mathrm{l} \mathrm{CSF} \mathrm{samples} \mathrm{according} \mathrm{to} \mathrm{the} \mathrm{manufactur-}$ er's instructions. The lowest detectable level was $22.47 \mathrm{pg} / \mathrm{ml}$. The interassay variability (assessed by replicate analysis of a $250 \mathrm{pg} / \mathrm{ml}$ standard) was $0.31 \%$.

Image processing and statistical analysis. Confocal photomicrographs between matched brain sections were taken using a Zeiss LSM710 under identical microscope conditions. Images were merged with NIH ImageJ software. Photomicrographs were collected only to show representative images. Data were graphed and analyzed using GraphPad Prism 5. Comparisons between two groups at a single time point were performed using two-tailed Student's $t$ test. Comparisons among three or more groups used a one-way ANOVA with post hoc Bonferonni-corrected $t$ test. All comparisons involving two treatments or multiple time points used twoway ANOVA followed by post hoc Bonferonni-corrected $t$ test. Differences between groups were considered significant when $p<0.05$. 

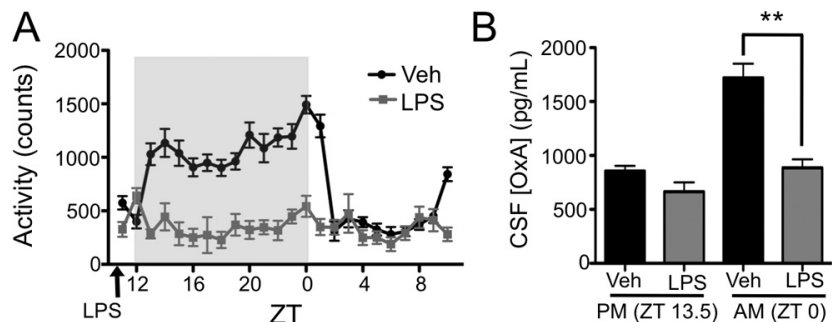

Figure 1. LPS-induced inhibition of home-cage LMA is associated with reduced dark-phase accumulation of $0 x A$ in the CSF. $A$, Home-cage LMA in rats receiving intraperitoneal LPS versus veh just before the onset of the dark phase. $B, 0 X A$ in the CSF collected either at ZT 13.5 or ZT 0 from LPS- or veh-treated rats. Data are expressed as mean \pm SEM. ${ }^{* *} p<0.01$.
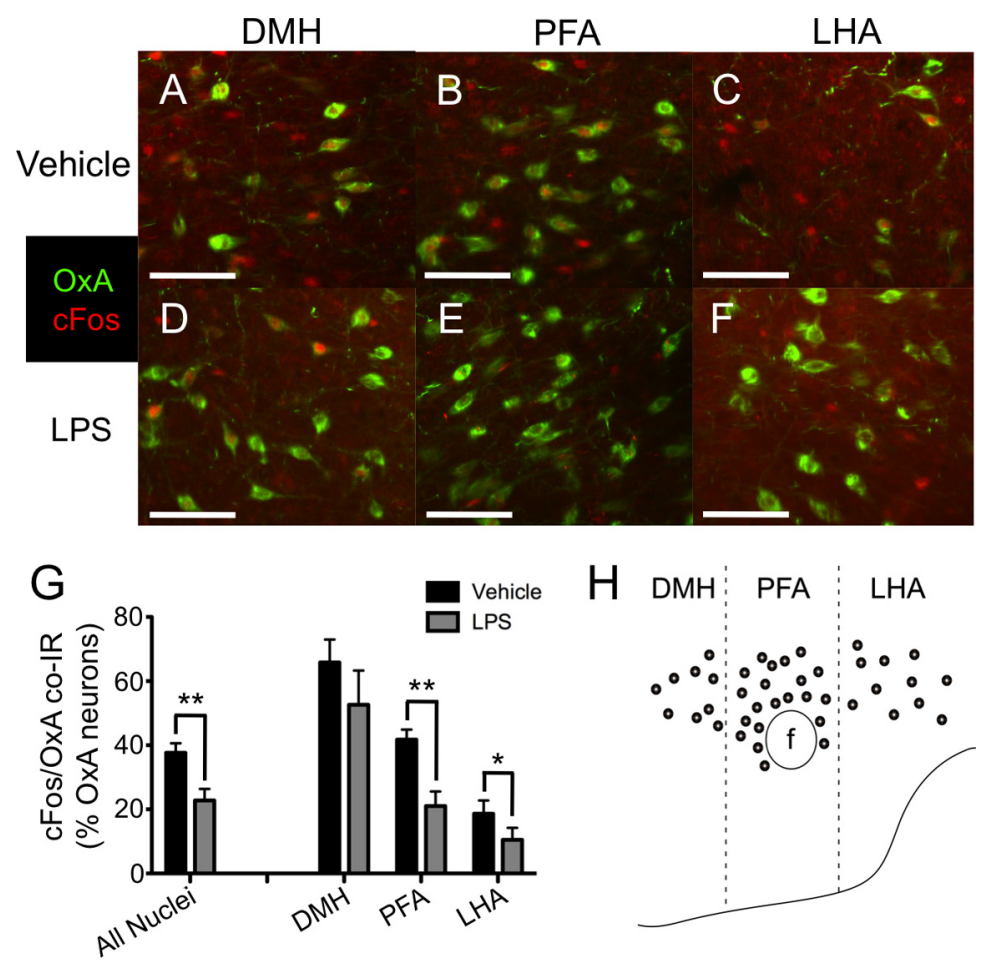

Figure 2. LPS treatment blocks the vespertise rise in cFos IR in 0x neurons. $\boldsymbol{A}-\boldsymbol{H}$, High-power representative photomicrographs of CFos IR in 0x neurons in DMH $(\boldsymbol{A}, \boldsymbol{D})$, PFA $(\boldsymbol{B}, \boldsymbol{E})$, and LHA $(\boldsymbol{C}, \boldsymbol{F})$ in veh- and LPS-treated rats. $\boldsymbol{G}$, Percentage of $0 \mathrm{x}$ IR neurons exhibiting CFos IR following treatment with intraperitoneal LPS or veh. Percentage of colocalization expressed as total $0 x$ neurons and by anatomic location. $\boldsymbol{H}$, Schematic illustrating division among DMH, PFA, and LHA Ox neuron populations. Data are expressed as mean \pm SEM. ${ }^{*} p<0.05 ;{ }^{* *} p<0.01$. Scale bars, $100 \mu \mathrm{m}$. f, Fornix.

\section{Results}

LPS-induced inhibition of home-cage LMA is associated with suppressed dark-phase $\mathrm{Ox}$ signaling

Diminished voluntary home-cage LMA is a hallmark behavior associated with both sickness and insufficient Ox signaling. To investigate a possible connection, rats were injected with LPS $(250 \mu \mathrm{g} / \mathrm{kg}, n=7)$ or veh $(n=10) 90 \mathrm{~min}$ before lights off (ZT $10.5)$. We observed nearly complete inhibition of the normal dark-phase LMA in LPS-treated animals (Fig. $1 A$ ). This experiment was repeated with the addition of CSF collection either at lights off or just before lights on, at the zenith of CSF Ox concentration (Desarnaud et al., 2004). We measured a significant decrease in CSF OxA concentration in LPS-treated animals $(n=6)$ compared with veh $(n=5)$ at ZT 0 , suggesting reduced Ox release throughout the dark phase in these animals (LPS, $887 \pm 78 \mathrm{pg} / \mathrm{ml}$; veh, $1720 \pm 130 \mathrm{pg} / \mathrm{ml} ; p<0.001)$, though no significant change was observed at the onset of the dark phase, during the nadir of OxA concentration (Fig. $1 B$ ). This is unlikely to be a transcriptional effect, as no change in pre-proorexin $(O x)$ mRNA expression was observed 1 or $8 \mathrm{~h}$ after LPS administration (mRNA quantity relative to vehicle; LPS $1 \mathrm{~h}$, $0.98 \pm 0.1$-fold; LPS 8 h, $0.97 \pm 0.1$-fold; n.s.).

In nocturnal rodents, the activity of Ox neurons increases during the dark phase, coincident with increased Ox release, and increased wakefulness and activity (Estabrooke et al., 2001; Martínez et al., 2002). We examined whether LPS administration just before onset of the dark phase suppresses the vespertine induction of cFos IR in Ox neurons. LPS-treated rats $(n=4)$ exhibited significantly reduced cFos IR in Ox neurons compared with controls $(n=3 ; p<0.01)$ (Fig. $2 A-H)$. Because anatomically distinct populations of Ox neurons may have different functions (Harris and Aston-Jones, 2006), colocalization was quantified in dorsomedial nucleus $(\mathrm{DMH})$, perifornical area (PFA), and lateral LHA subpopulations (Fig. $2 \mathrm{H}$, description of anatomy). Twoway ANOVA showed a significant effect of treatment $\left(F_{(1,15)}=25.35 ; p<0.001\right)$ and anatomic location $\left(F_{(2,15)}=87.18 ; p<\right.$ $0.001)$. No change in cFos IR was observed in DMH Ox neurons; however, post hoc analysis by Bonferroni-corrected $t$ test demonstrated a significant decrease in cFos IR in both PFA $(p<0.01)$ and LHA $(p<0.05) \mathrm{Ox}$ neurons (Fig. $2 A-H$ ). No effect of rostrocaudal location on Ox neuron cFos IR was observed. The number of Ox IR neurons counted did not differ between treatment groups (total: veh, $1075 \pm 159$ cells; LPS, $1123 \pm 90.1$ cells; DMH: veh, $196.3 \pm 48.7$ cells; LPS, $189.8 \pm 23.6$ cells; PFA: veh, $492.5 \pm 38.9$ cells; LPS, $546.5 \pm 58.9$ cells; LHA: veh, $386.3 \pm 97.6$ cells; LPS, $386.8 \pm$ 28.3 cells).

\section{Central (intracerebroventricular) $\mathbf{O x A}$} replacement prevents the onset of LPS-induced lethargy

To test the hypothesis that a specific inhibition of $\mathrm{Ox}$ signaling underlies the reduced LMA exhibited by LPS-treated rats, we undertook a series of intracerebroventricular OxA replacement studies. We found that central OxA administration influences LMA and arousal for $\sim 90$ min after injection (data not shown), in accordance with previous studies (Hagan et al., 1999). We also found that a $1 \mu \mathrm{g}$ bolus intracerebroventricular injection of OxA had no significant effect on LMA in healthy rats (data not shown). Because the duration of $\mathrm{Ox}$ action is relatively short compared with the behavioral effects of LPS, we tested the effect of Ox replacement in the following three paradigms: (1) acute LPS-induced lethargy prevention; (2) acute dark-phase lethargy reversal; and (3) subchronic (overnight) OxA infusion. In the acute lethargy prevention experiment (experiment 1), rats treated with intraperitoneal LPS or veh at ZT 10.5 were administered intracerebroventricular OxA or aCSF at ZT 11.5, 30 min before onset of the dark period ( $n=6 /$ group). While OxA had no effect on LMA in veh-treated rats, OxA restored LMA in LPS-treated rats to nearcontrol levels during the subsequent 90 min (Fig. $3 \mathrm{~A}, \mathrm{~B}$ ). Follow- 

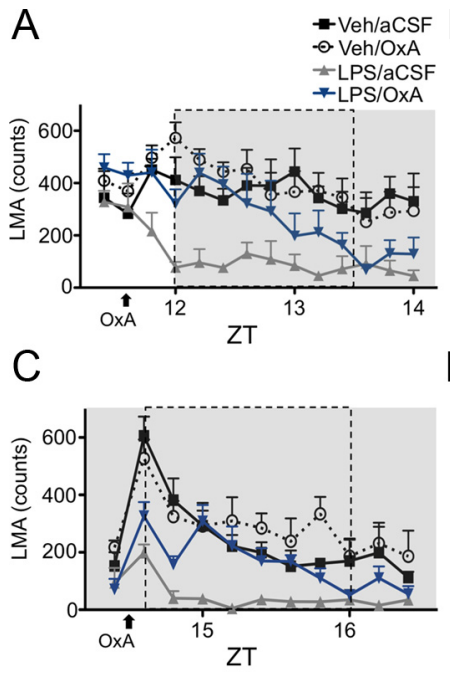

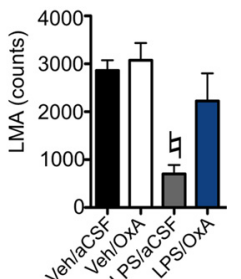

$\mathrm{D}_{3}$

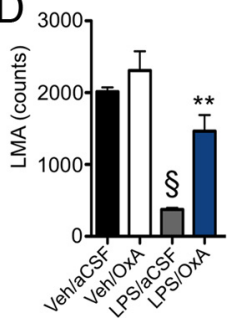

Figure 3. Central bolus $0 x A$ replacement prevents and reverses LPS-induced lethargy. $\boldsymbol{A}$, Effect of intracerebroventricular OxA versus aCSF administration on voluntary LMA in LPS- versus veh-treated rats during transition from light phase to dark phase. Movement data expressed in 12 min intervals. $\boldsymbol{B}$, Sum total of voluntary home-cage movement during first 90 min of dark phase in rats treated with intraperitoneal LPS versus veh and intracerebroventricular $0 \mathrm{xA}$ or veh. Period of summed data outlined by dotted line in $\boldsymbol{A}$. $\boldsymbol{C}$, Effect of $0 x A$ versus aCSF administration on voluntary LMA in LPS- versus veh-treated rats during dark phase, after onset of lethargy. LMA expressed in 12 min intervals. D, Sum total of LMA in rats treated with intraperitoneal LPS during $90 \mathrm{~min}$ following intracerebroventricular $0 x A$ versus veh. Period of summed data outlined by dotted line in $\boldsymbol{C}$. Shaded region in $\boldsymbol{A}$ and $\boldsymbol{C}$ indicates dark phase; arrows indicate time of intracerebroventricular injection. Data are expressed as mean \pm SEM. ${ }^{*} p<0.05$ versus LPS/0xA and veh/aCSF; ${ }^{\S} p<0.01$ versus LPS/0xA and veh/aCSF; ${ }^{* *} p<0.01$ versus veh/0xA and LPS/aCSF.

ing this period, LPS/OxA rats reduced their activity to the level of LPS/aCSF rats for the remainder of the dark phase.

In the lethargy reversal experiment (experiment 2), rats were treated with LPS versus veh and subsequently centrally injected with OxA (veh/OxA, $n=4$; LPS/OxA, $n=6$ ) versus aCSF (veh/ aCSF, $n=3$; LPS/aCSF, $n=3$ ) at ZT 15, $3 \mathrm{~h}$ after the onset of the dark phase. We found that LPS inhibited LMA compared with veh and that this was reversed by OxA administration during the 90 min following treatment (Fig. 3C,D). Post hoc analysis demonstrated significant differences between veh/aCSF and LPS/ aCSF groups $(p<0.001)$ as well as between LPS/OxA and LPS/ aCSF groups $(p<0.05)$.

In the subchronic OxA administration experiment (experiment 3), rats were implanted with intracerebroventricular minipumps to deliver OxA ( $3 \mu \mathrm{g} / \mathrm{h}$ ) or aCSF throughout the dark phase, with ad libitum access to food. This dose elicits no acute or chronic effects on body weight, food intake, brown adipose temperature, plasma corticosterone, or fat depot mass in rats (Haynes et al., 1999). Rats were treated with LPS or vehicle at ZT 10.5 , as described above, yielding three groups — veh/aCSF $(n=$ $10)$, LPS/aCSF $(n=7)$, and LPS/OxA $(n=7)$. Though both LPS-treated groups moved significantly less than vehicle-treated controls, LPS/OxA-treated rats showed an amelioration of this effect throughout the dark phase (Fig. 4A,B). Post hoc analysis of dark phase and total $24 \mathrm{~h}$ LMA demonstrated a significant effect of OxA treatment on LPS-treated rats $(p<0.05)$. OxA treatment reinstated normal crepuscular LMA peaks, which are suppressed in the LPS/aCSF rats. OxA treatment had no effect on either food intake or body weight in LPS-treated rats (Fig. 4C,D), suggesting that the increase in LMA was not due to increased feeding behavior.
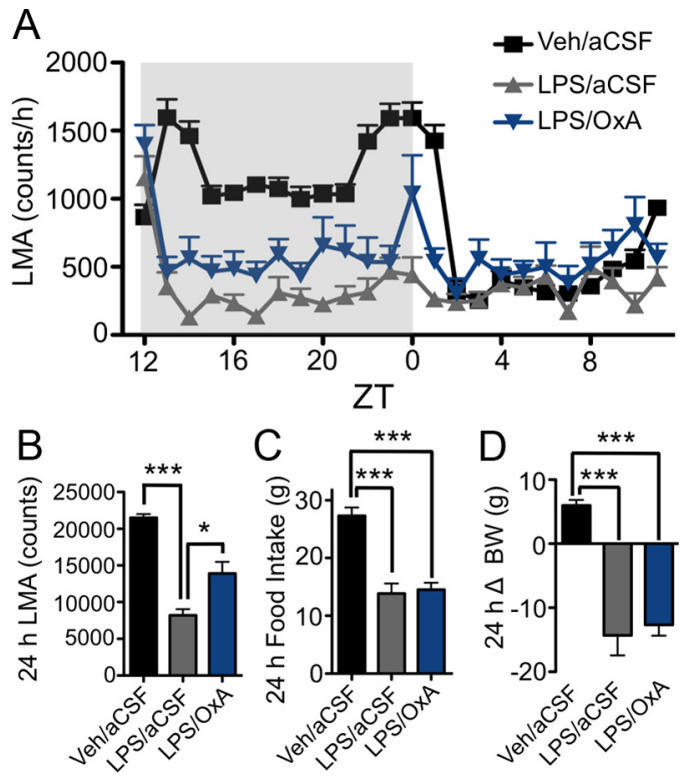

Figure 4. Continuous intracerebroventricular OxA infusion ameliorates LPS-induced decreases in LMA. $A$, Effect of continuous central $0 x A$ or veh infusion on voluntary LMA in LPS- or veh-treated rats. Movement data expressed as hourly sums. LPS administered at ZT 10.5. 0XA onset between ZT 8 and ZT 10. Shaded region indicates dark phase. $B$, Sum total of voluntary LMA during $24 \mathrm{~h}$ following LPS administration (ZT 12-ZT 12). C, Effect of LPS and OxA on $24 \mathrm{~h}$ food intake. $D$, Changes in body weight during $24 \mathrm{~h}$ following treatment with LPS and 0x. Data are expressed as mean \pm SEM. ${ }^{*} p<0.05 ;{ }^{* * *} p<0.001$.

\section{LPS blocks FAA and Ox neuron activity in food-entrained rats}

Twenty-four hour cyclic FR paradigms induce entrainment of biological rhythms to adapt to the period of food availability. This behavior is marked by an increase in LMA in the period immediately preceding food availability (FAA) that is dependent on $\mathrm{Ox}$ signaling but independent of suprachiasmatic nucleus master clocks, which remain phase locked to the light/dark cycle (Wakamatsu et al., 2001; Mieda et al., 2004). Therefore, we undertook several studies investigating the effect of inflammation on FAA and the concomitant increase in Ox neuron activity. We first evaluated whether intraperitoneal LPS could inhibit FAA, and whether central OxA administration could restore this behavior. As with the animals entrained to food restriction, LMA maxima shifted from two crepuscular peaks to a single activity peak during the hour preceding feeding (Fig. $5 A$ ). FR rats were injected intraperitoneally with LPS or vehicle at ZT 1.5 and subsequently were treated intracerebroventricular with OxA or aCSF at ZT 3 ( $n=7-9$ /group). We found that LPS potently inhibited FAA compared with vehicle treatment, but that OxA treatment restored activity during this period to control levels. OxA treatment had no significant effect on veh-treated rats (Fig. $5 B, C$ ). LPS inhibited food intake, and this effect was not reversed following OxA treatment (Fig. 5D). To determine whether Ox neurons are inhibited in this paradigm, the above experiment was repeated without intracerebroventricular injection, and rats were killed at ZT 3.5, during the peak of FAA. As a control for the effects of food restriction, a group of ad libitum fed, veh-treated rats were killed at the same time ( $n=4$ /group). We found that FR significantly increased cFos IR in Ox neurons compared with ad libitum fed animals, but that LPS treatment significantly reduced the percentage of total Ox neurons exhibiting cFos IR compared with vehicle $\left(F_{(2,27)}=72.37 ; p<0.001\right)$ (Fig. $\left.5 E, F\right)$. When counted by anatomic location, we found that FR specifically activated $\mathrm{Ox}$ 
A
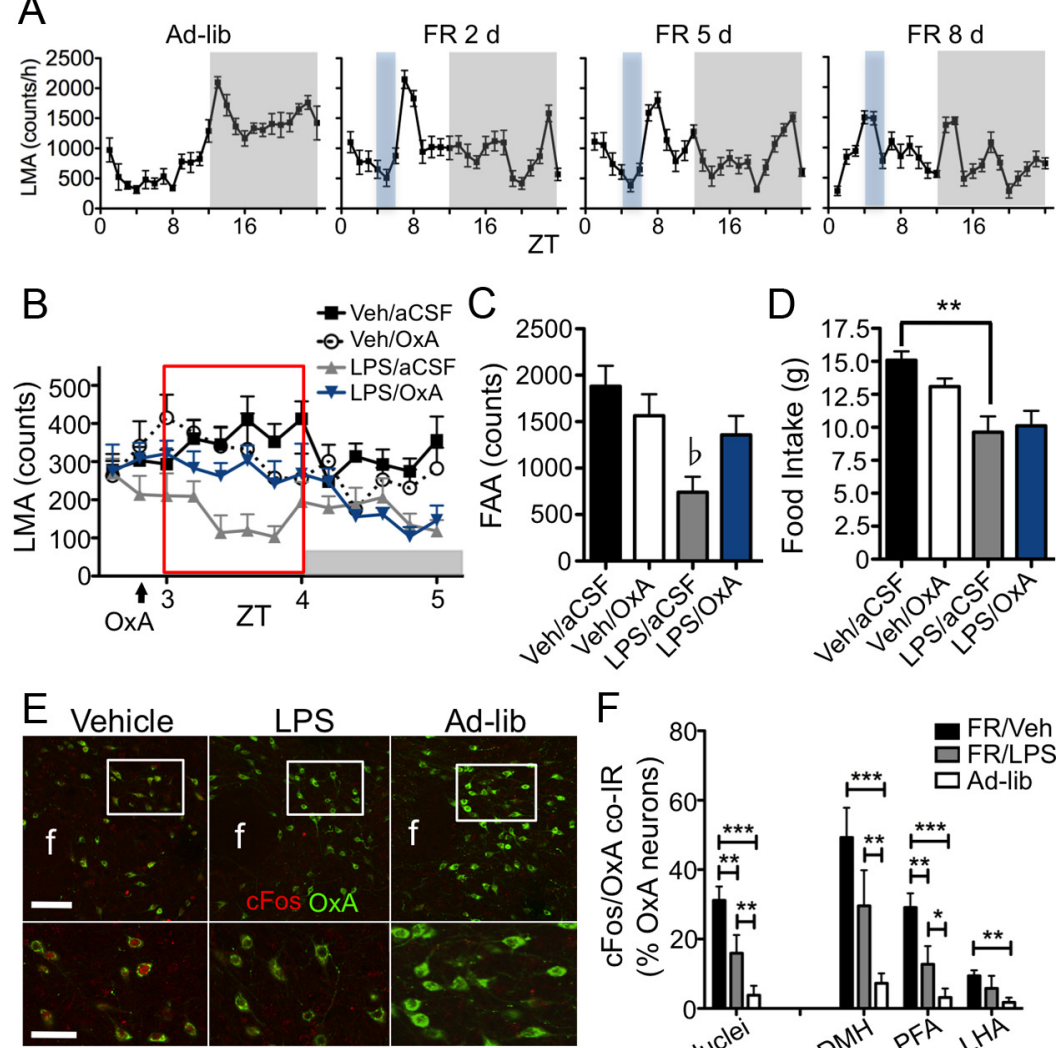

$\mathrm{F}$

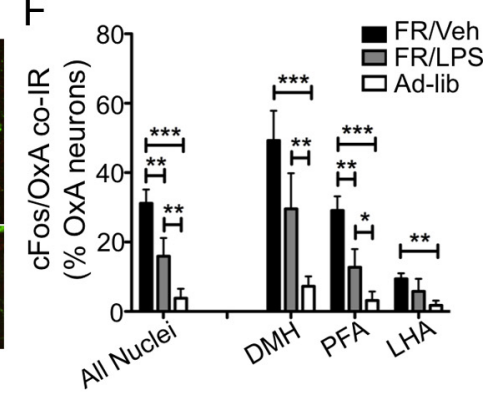

G

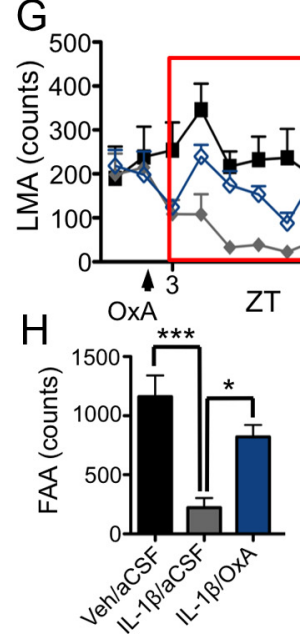

$\because$ Veh/aCSF

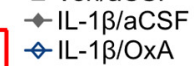
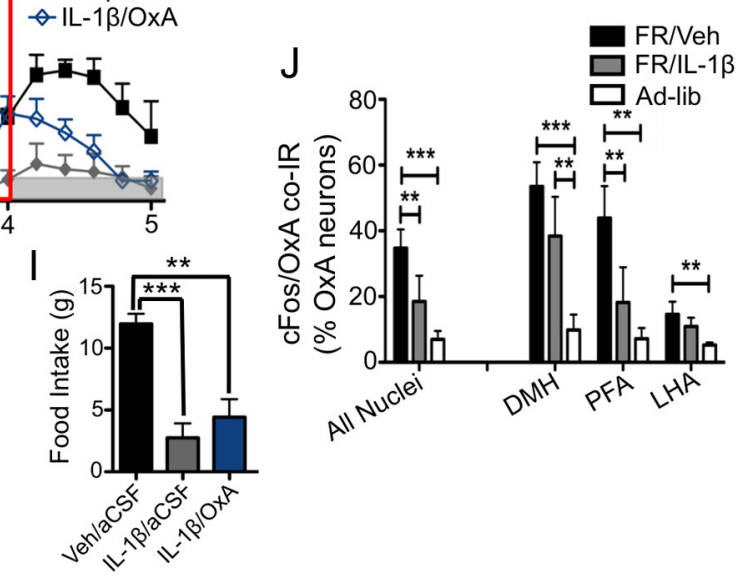

Figure 5. Central $0 x A$ administration restores FAA in FR rats treated with intraperitoneal LPS or intracerebroventricular IL-1 $\beta$. $A$, Changes in volitional LMA patterns in response to $8 \mathrm{~d}$ of food restriction. Animals fed from ZT 4 to ZT 6 each day (blue shading). Gray-shaded region represents dark phase. $\boldsymbol{B}$, Inhibition of FAA by intraperitoneal LPS and restoration with central OXA in foodentrained rats. Movement is plotted in $12 \mathrm{~min}$ intervals. Gray bar indicates introduction of food into cages. Arrow denotes treatment with $0 x A$ or aCSF. C, Sum of FAA (home-cage activity during the hour before food presentation) in LPS-versus veh-treated FR rats treated with intracerebroventricular OxA or aCSF. Period of FAA is indicated by a red box in $\boldsymbol{B}$. D. Food intake from ZT 4 to ZT 6 following LPS versus veh and OXA versus aCSF treatment. Percentage of colocalization expressed as total $0 \mathrm{x}$ neurons and by anatomic location. $\boldsymbol{E}$, Low-power (top) and high-power (bottom) representative photomicrographs of cFos IR (red) in 0x neurons (green) in PFA from veh- and LPS-treated FR rats and ad libitum fed controls. $F$, Percentage of $0 x$ IR neurons exhibiting cFos IR in FR rats following treatment with intraperitoneal LPS or veh. Ad libitum, veh-treated rats also quantified as a control for FR rats. G, FAA in FR rats treated with intracerebroventricular IL-1 $\beta$ versus veh and restoration with $0 x A$. Movement is plotted in 12 min intervals. Gray bar indicates introduction of food into cages. Arrow denotes treatment with 0xA or aCSF. $\boldsymbol{H}$, Sum of FAA (home-cage activity during the hour before food presentation) in IL-1 $\beta$-versus veh-treated FR rats and $0 \times A$-replaced, IL-1 $\beta$-treated rats. Period of FAA indicated by red box in $\mathbf{G}$. $I$, Food intake during $2 \mathrm{~h}$ of food access following treatment with IL-1 $\beta$ or veh and $0 \mathrm{xA}$ or aCSF. J, Percentage of $0 x$ IR neurons exhibiting cFos IR in FR rats following treatment with intracerebroventricular IL- $\beta$ or veh. Ad libitum, veh-treated rats also counted as a control for FR. Percentage colocalization expressed as total $0 x$ neurons and by anatomic location. Data are expressed as mean \pm SEM. ${ }^{*} p<0.05 ;{ }^{* *} p<0.01 ;{ }^{* * *} p<0.001$. Scale bars: $\boldsymbol{E}$, top panels, $100 \mu \mathrm{m} ; \boldsymbol{E}$, bottom panels, $50 \mu \mathrm{m}$. neurons in the DMH and PFA, but not in the LHA. The LPS-induced suppression of Ox neuron activity was localized to the PFA regions of neurons $(p<0.001)$, while no difference was observed between veh- or LPS-treated FR rats in the DMH or LHA populations. No difference in the total number of Ox IR neurons was observed between groups (total: FR/veh, $1164 \pm 59.9$ cells; FR/LPS, $1093 \pm 123$ cells; ad libitum, $1173 \pm 147$ cells; DMH: FR/veh, $201.8 \pm$ 42.8 cells; FR/LPS, $191.8 \pm 35.1$ cells; ad libitum, $210.5 \pm 13.1$ cells; PFA: FR/veh $515.0 \pm 70.5$ cells; FR/LPS, $469.8 \pm 52.5$ cells; ad libitum, $514.5 \pm 68.7$ cells; LHA: FR/veh, $447.0 \pm 35.4$ cells; FR/LPS, $431.0 \pm$ 68.6 cells; ad libitum, $448.3 \pm 87.3$ cells). Previous studies demonstrated that calorie restriction dampens cytokine responses to proinflammatory stimuli (Lord et al., 1998). Two hours following LPS treatment, we found that the induction of serum IL-6 and hypothalamic inflammatory markers [IL$1 \beta$, IL-6, SOCS-3 (suppressors of cytokine signaling-3), $\mathrm{I} \kappa \mathrm{B} \alpha]$ remained intact in $\mathrm{FR}$ rats (Table 1).

\section{Central IL-1 $\beta$ blocks FAA and Ox} neuron activity in food-entrained rats To test whether central inflammation in the absence of peripheral inflammation is sufficient to suppress Ox neuron activity and FAA, we measured LMA and food intake in FR rats following intracerebroventricular administration of the inflammatory cytokine IL- $1 \beta$. Rats were then treated with central OxA or vehicle, as described above ( $n=5$ /group). IL- $1 \beta$ treatment potently blocked FAA, and this effect was ameliorated by OxA administration with no effect on food intake (Fig. $5 G-J)$. Two-way ANOVA showed a significant effect of both treatment $\left(F_{(1,21)}=\right.$ $21.31 ; p<0.001)$ and anatomic location $\left(F_{(2,21)}=35.72 ; p<0.001\right)$ on the IHC colocalization of cFos and OxA as well as an interaction between these variables $\left(F_{(2,21)}=3.886 ; p<0.05\right)$ (Fig. 5J). Post hoc analysis revealed that food restriction induced cFos IR in DMH and PFA Ox neurons, while IL- $1 \beta$ specifically reduced cFos IR in PFA Ox neurons, with no significant effect on either DMH or LHA populations (PFA, $p<0.001$ ). No significant differences between total Ox IR neurons were observed between treatment groups (total: FR/veh, $1158 \pm 68.1$ cells; FR/IL-1 $\beta, 1091 \pm 151$ cells; ad libitum, $1190 \pm 175$ cells; DMH: FR/veh, $200.0 \pm$ 37.3 cells; FR/ IL- $1 \beta, 191.3 \pm 43.0$ cells; ad libitum, $217.0 \pm 2.0$ cells; PFA: FR/veh, $524.6 \pm 75.0$ cells; FR/ IL-1 $\beta, 452.0 \pm 47.4$ cells; ad libitum, $505.3 \pm 81.1$ cells; LHA: 
FR/veh, $433.8 \pm 42.5$ cells; FR/ IL-1 $\beta, 447.7 \pm 73.5$ cells; ad libitum, $467.7 \pm 95.8$ cells). These data demonstrate that central inflammation is sufficient to suppress FAA in an Ox-dependent manner and suggest that central and peripheral inflammatory challenges share a common pathway for suppressing PFA Ox neuron activity.

\section{Ox neurons are not direct targets for inflammatory signaling} Because inflammatory cytokines directly modulate the activity of hypothalamic melanocortin and thermoregulatory neurons, we tested whether Ox neurons also respond directly to cytokines. Using dual-label in situ hybridization, we did not observe colocalization of IL-1RI, LIF-R, or TNF-R mRNA with $O x$ mRNA (Fig. 6A, $C, D$ ). Further, we assessed whether Ox neurons receive direct inflammatory input by measuring the expression of $\mathrm{I} \kappa \mathrm{B} \alpha$, which is induced in response to activation of the inflammatory nuclear factor (NF)- $\kappa \mathrm{B}$ signaling pathway. Though we observed $\mathrm{I} \kappa \mathrm{B} \alpha$ expression in the LHA of LPS-treated rats, $\mathrm{I} \kappa \mathrm{B} \alpha$ did not colocalize with $O x$, indicating that $\mathrm{Ox}$ neurons do not directly respond to proinflammatory signals (Fig. 6B).

Because intracerebroventricular IL- $1 \beta$ is sufficient to suppress FAA in FR rats, we tested whether central IL-1 signaling is necessary for the induction of lethargy by LPS. Although LPS suppressed vespertine LMA compared with vehicle $\left(F_{(1,18)}=\right.$ 32.64; $p<0.001)$, coadministration of intracerebroventricular IL-1 receptor antagonist (IL-1ra; $4 \mu \mathrm{g}$ ) with intraperitoneal LPS at ZT 10.5 ( $n=5-6$ /group) had no effect on vespertine (ZT 12-ZT 14) LMA in LPS- or veh-treated rats (veh/veh, $2435 \pm 170$ counts; veh/LPS, $840.0 \pm 210$ counts; IL-1ra/veh, $1899 \pm 253$ counts; IL-1ra/LPS, $1027 \pm 211$ counts; $F_{(1,18)}=$ 2.804; $p=0.11$ ), despite ameliorating LPS-induced anorexia (veh/veh, $25.6 \pm$ $2.4 \mathrm{~g}$; veh/LPS, $8.78 \pm 1.9 \mathrm{~g}$; IL-1ra/veh, $22.4 \pm 2.5 \mathrm{~g} ;$ IL-1ra/LPS, $16.6 \pm 2.5 \mathrm{~g}$; $\left.F_{(1,18)}=5.397 ; p<0.05\right)$. We observed that IL-1 ra partially restored LMA in LPStreated rats $\sim 8 \mathrm{~h}$ following treatment, suggesting a role for IL-1 signaling in propagating the acute behavioral response to LPS.

Several studies have further implicated that PG signaling is an essential step in the induction of sickness behavior (Crestani et al., 1991; Serrats et al., 2010). Systemic (intraperitoneal) pretreatment with the nonselective COX-1/2 inhibitor indomethacin $(4 \mathrm{mg} / \mathrm{kg})(n=5-6 /$ group $)$ at ZT 10 potently blocked LPSinduced pyresis (peak $\Delta \mathrm{T}$ : veh/veh, $1.88 \pm 0.2^{\circ} \mathrm{C}$; indo/veh, $1.97 \pm 0.2^{\circ} \mathrm{C}$; veh/LPS, $4.13 \pm 0.5^{\circ} \mathrm{C}$; indo/LPS, $1.94 \pm 0.1^{\circ} \mathrm{C}$; two-way ANOVA, interaction $F_{(1,18)}=16.76 ; p<0.001$ ), but no significant effect on LMA was observed (veh/veh, $2474 \pm 321$ counts; indo/veh, $2617 \pm 406$ counts; veh/LPS, $1439 \pm 241$ counts; indo/LPS, $1793 \pm 228$ counts). Statistical analysis by twoway ANOVA demonstrated a significant effect of LPS treatment on LMA $\left(F_{(1,18)}=8.278 ; p<0.05\right)$, but no effect of indomethacin and no interaction between treatments. Central pretreatment
Table 1. FR rats exhibit normal inflammatory response to LPS

\begin{tabular}{|c|c|c|c|c|}
\hline & \multicolumn{2}{|c|}{ mRNA fold-change, LPS vs vehicle } & \multicolumn{2}{|c|}{$\begin{array}{l}\text { 2-way ANOVA } \\
\text { (interaction) }\end{array}$} \\
\hline & Ad libitum & FR & $F_{(1,18)}$ & $p$ \\
\hline \multicolumn{5}{|l|}{ Genes } \\
\hline$/ / 1 b$ & $16.68 \pm 4.3$ & $27.46 \pm 6.1$ & 0.076 & 0.786 \\
\hline 116 & $7.23 \pm 2.7$ & $2.73 \pm 0.7$ & 2.186 & 0.157 \\
\hline Socs3 & $3.82 \pm 1.1$ & $2.97 \pm 0.7$ & 0.249 & 0.624 \\
\hline Nfkbia & $5.16 \pm 0.6$ & $3.01 \pm 0.5$ & 2.883 & 0.107 \\
\hline \multicolumn{5}{|c|}{ Serum protein } \\
\hline IL-6 & $5882 \pm 1660(\mathrm{pg} / \mathrm{ml})$ & $3593 \pm 1070(\mathrm{pg} / \mathrm{ml})$ & 1.696 & 0.210 \\
\hline
\end{tabular}

Hypothalamic mRNA levels of inflammatory cytokines in ad libitum fed versus FR rats following LPS treatment. Data are normalized to 18 S RNA quantity and expressed as relative quantity compared to vehicle treatment. Serum IL-6 i expressed as serum protein concentration following LPS (vehicle-treated mean $=158.3 \pm 80.6 \mathrm{pg} / \mathrm{ml}$ ). Data are expressed as mean \pm SEM.

Figure 6. $0 x$ neurons are not direct targets for inflammatory signaling. $\boldsymbol{A}$, Representative low-power photomicrograph of a

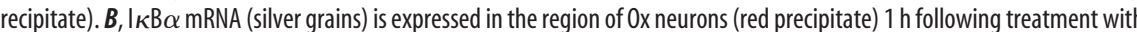

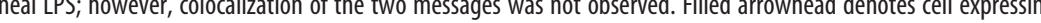
but does not colocalize with OxmRNA (red precipitate). Filled arrowhead denotes cell expressing LIF-R but not Ox Open arrowhead signifies cell that expresses $0 x$ but not LIF-R. D, TNF-R mRNA (silver grains) is expressed in LHA, but is not expressed by $0 x$ neurons (red precipitate). Scale bars: $\boldsymbol{A}-\boldsymbol{D}$, low power, $200 \mu \mathrm{m} ; \boldsymbol{B}-\boldsymbol{D}$, inset, $50 \mu \mathrm{m}$. 3V, Third ventricle; f, fornix.

with the COX-2-specific NS-398 (5 $\mu \mathrm{g}$ ) also suppressed the febrile response to LPS but, like indomethacin, had no significant effect on LMA (data not shown). Together, these data demonstrate that neither central IL-1 signaling nor PG signaling is required to produce lethargy in response to LPS.

\section{LPS-induced lethargy is not melanocortin dependent}

These results indicate that the LPS-induced inhibitory input onto $\mathrm{Ox}$ neurons is mediated by a proximal, inflammationsensitive neuron population. We tested whether inflammationinduced activation of central melanocortin signaling could relay this information by assessing the expression of melanocortin receptors on Ox neurons using dual-label in situ hybridization. We found no coexpression of either the type 4 

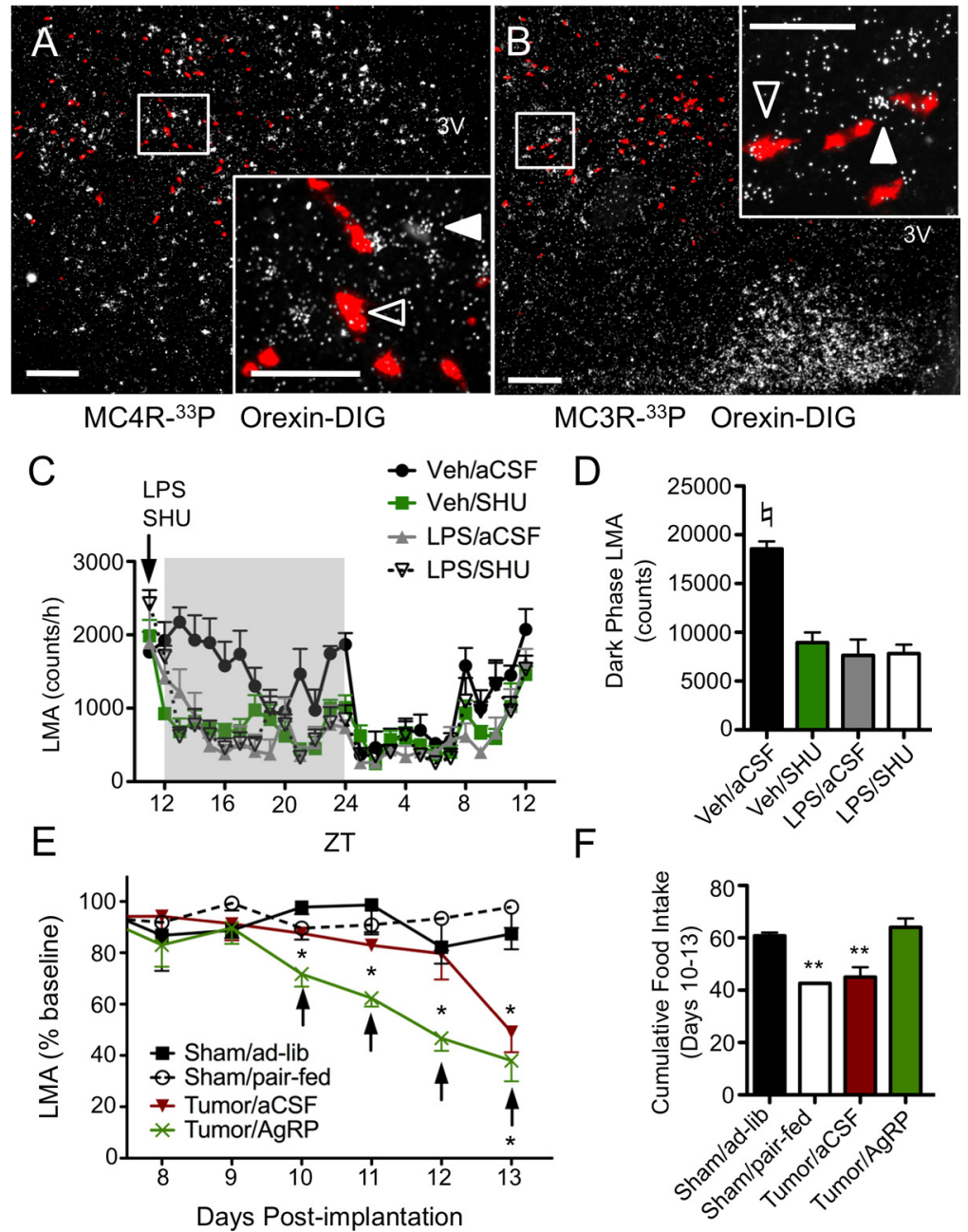

$\mathrm{F}$

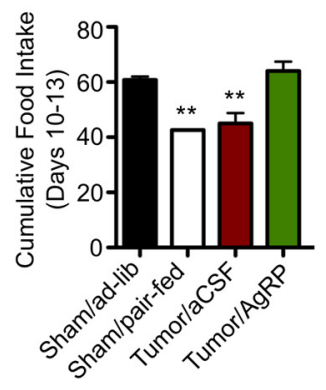

Figure 7. LPS-induced lethargy is not melanocortin dependent. $\boldsymbol{A}, \boldsymbol{B}$, Double-label in situ hybridization showing no colocalization of Ox mRNA (red precipitate) with either MC4R ( $\boldsymbol{A}$, silver grains) or MC3R ( $\boldsymbol{B}$, silver grains). $\boldsymbol{C}$, Hourly LMA from animals cotreated with intraperitoneal LPS or veh and intracerebroventricular SHU-9119 or aCSF. Arrow denotes treatment time. $\boldsymbol{D}$, Summed overnight LMA from study depicted in $\boldsymbol{C}$. $\boldsymbol{E}$, Daily LMA, measured as a percentage of each animal's baseline daily LMA, from tumor-bearing and sham-operated rats. Tumor-bearing rats were treated with intracerebroventricular AgRP or aCSF. Shamoperated animals were fed ad libitum or pair-fed with tumor-bearing rats and treated with aCSF. Arrows denote intracerebroventricular treatment days. $\boldsymbol{F}$, Cumulative food intake during intracerebroventricular treatment period from study in $\boldsymbol{E}$ demonstrating that AgRP restores feeding in tumor-bearing animals to sham-operated/pair-fed levels. Data are expressed as mean \pm SEM. " $p<$ 0.001 versus veh/SHU, LPS/aCSF, and LPS/SHU; ${ }^{*}<0.05$ versus sham-operated/ad libitum and sham-operated/pair-fed; ${ }^{* *} p<$ 0.01 vs sham-operated/ad libitum and tumor/AgRP). Scale bars: low power, $200 \mu \mathrm{m}$; inset, $50 \mu \mathrm{m}$.

(MC4R) or type 3 (MC3R) melanocortin receptors in cells expressing $O x$ (Fig. $7 A, B$ ).

We tested the potential role of increased melanocortinergic tone on the suppression of LMA by administering the nonspecific MC3R/MC4R antagonist SHU-9119 (1 nmol) in animals treated with LPS versus veh ( $n=4-6 /$ group). Food was removed from the cages to control for feeding-induced suppression of LMA. Pharmacologic blockade of melanocortin receptors in LPS-treated animals did not increase LMA, and SHU treatment alone suppressed LMA to levels approximating those of LPS (Fig. $7 C, D)$. We also tested the effects of melanocortin blockade on LMA and food intake in a tumor-bearing rat model of chronic inflammation. Tumor-bearing or sham-implanted rats were centrally treated with the endogenous MC3R/MC4R antagonist, AgRP ( $1 \mathrm{nmol}$ ), or aCSF during the final $4 \mathrm{~d}$ of the experiment. The sham animals were either fed ad libitum or pair-fed with tumor-bearing animals and were treated with aCSF, yielding four groups (sham/ad libitum, sham/pair-fed, tumor/aCSF, tumor/AgRP: $n=3$ /group). Nightly administration of AgRP did not ameliorate lethargy in tumor-bearing rats, despite restoring food intake (Fig. 7E,F). Again, melanocortin antagonism suppressed LMA in healthy (sham-operated) rats.

Arcuate POMC neurons release both $\alpha$-melanocyte-stimulating hormone, which binds MC3R and MC4R, and $\beta$-endorphin, which binds the opioid receptors. Opioids inhibit Ox neuron activity via the $\mu$-opioid receptor (OR), which is expressed by $\mathrm{Ox}$ neurons (Georgescu et al., 2003; Li and van den Pol, 2008). Blockade of central opioid signaling by intracerebroventricular pretreatment with the nonselective OR antagonist naltrexone $(10 \mu \mathrm{g})$ had no effect on vespertine LMA (veh/veh, $2011 \pm 130$ counts; NTX/veh, $2342 \pm 395$ counts; veh/ LPS, $703 \pm 151$ counts; NTX/LPS, $809 \pm$ 164 counts) or overnight food intake in LPS- or veh-treated rats ( $n=6$ /group).

LHA neurotensin neurons are activated during LPS-induced inflammation

LHA Nts-expressing neurons, many of which also express the long form of the leptin receptor (LepRb), provide an inhibitory input on Ox neurons when activated by leptin (Leinninger et al., 2011). Because leptin is closely structurally related to class I helical cytokines (Zhang et al., 1997) and shares intracellular signaling pathways with IL-6 family cytokines (Banks et al., 2000), we tested whether these neurons are also activated during inflammatory challenge. We injected male Nts-cre/GFP mice with LPS or veh $(n=$ 4/group) at ZT 10.5 and looked at cFos IR in Nts-IR and Ox-IR neurons at ZT 12.5. Because many cells in multiple nuclei express Nts, we counted only those cells that overlap with the Ox neuron distribution, where the Nts-LepRb + cells are located. We found a significant increase in the total number of Nts neurons with cFos-IR as well as the percentage of total Nts neurons colabeled with cFos in LPS-treated rats, but no difference in total Nts neurons per section between groups (Fig. $8 A-H$ ). This corresponded with a significant decrease in cFos IR in Ox neurons following LPS treatment (Fig. 8F, G,I). A small percentage of GFP-IR cells were also labeled for $\mathrm{Ox}(<1 \%)$, and cFos IR was not counted in these cells. This finding is consistent with the hypothesis that LHA Nts neurons are activated during inflammatory challenge and may contribute to the inhibition of Ox neuron activity.

Tumor-bearing rats exhibit decreased LMA and fewer medial Ox-expressing neurons

Behavioral inhibition has also been described in cancer patients and tumor-bearing animals (Dantzer, 2001; Ryan et al., 2007). We used a syngenic methylcholanthrene-induced sarcoma 

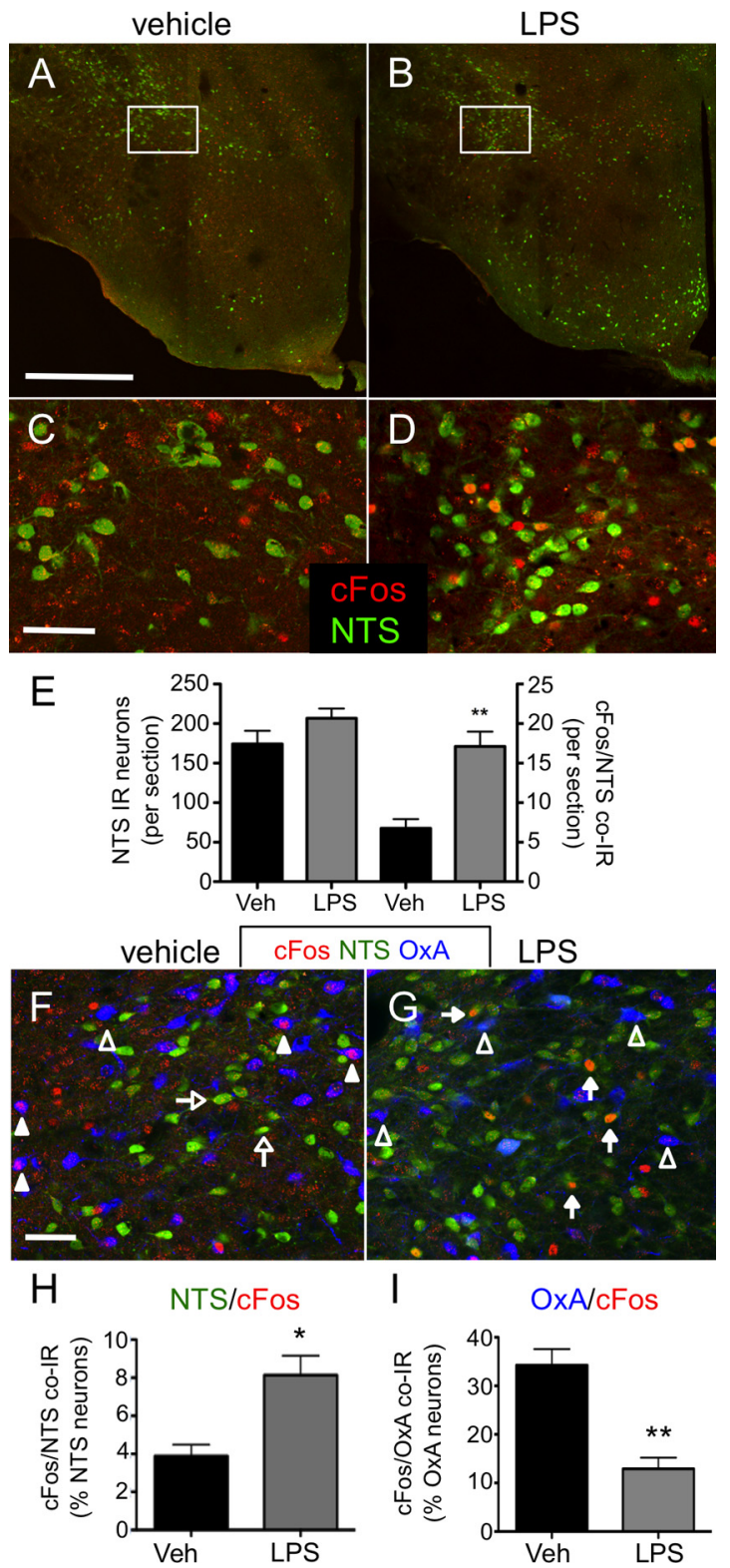

Figure 8. LPS treatment induces CFos IR in LHA NTS neurons while suppressing vespertine activation of $0 x$ neurons in NTS-cre/GFP mice. $A, B$, Low-power photomicrographs showing distribution of GFP IR (green) and cFos IR (red) in veh- ( $\boldsymbol{A}$ ) and LPS-treated ( $\boldsymbol{B}$ ) Nts-cre/GFP mice. $\boldsymbol{C}, \boldsymbol{D}$, High-power photomicrographs of regions outlined in $\boldsymbol{A}$ and $\boldsymbol{B}$. $\boldsymbol{E}$, Total number of LHA Nts-expressing neurons and number of neurons exhibiting GFP and cFos IR per section. $\boldsymbol{F}, \mathbf{G}$, Representative high-power images of sections triple labeled for GFP, CF0s, and OxA from vehand LPS-treated mice. $\boldsymbol{H}, \boldsymbol{I}$, Quantification of costaining for $\mathrm{CFos}$ (red) and GFP (green) $(\boldsymbol{H})$ or OxA (blue) (I) expressed as a percentage of neuropeptide-expressing cells. Filled arrows signify cells labeled with cFos and GFP; open arrows denote cells labeled with GFP alone. Filled arrowheads denote cells IR for both cFos and $0 x$; open arrowheads point to cells stained only for $0 x$. Data are expressed as mean \pm SEM. ${ }^{*} p<0.05 ;{ }^{* *} p<0.01$ versus veh. Scale bars: $\boldsymbol{A}, \boldsymbol{B}, 500$ $\mu \mathrm{m} ; \boldsymbol{C}, \boldsymbol{D}, \boldsymbol{F}, \mathbf{G}, 50 \mu \mathrm{m}$. 3V, Third ventricle; f, fornix.

model to evaluate the role of Ox signaling in the inhibition of volitional activity in tumor-bearing rats. Tumor-bearing animals $(n=12)$ exhibited a steady decline in total daily LMA during days $10-13$, when tumor growth is maximal, compared with shamoperated animals $(n=6)$. On the final day of the experiment (day 13 after implantation), tumor-bearing rats showed significantly less dark-phase activity compared with their own baseline activity (average of days 3-5 postimplantation) (Fig. 9A) and exhibit a significant decrease in $24 \mathrm{~h}$ LMA compared with sham-operated
A
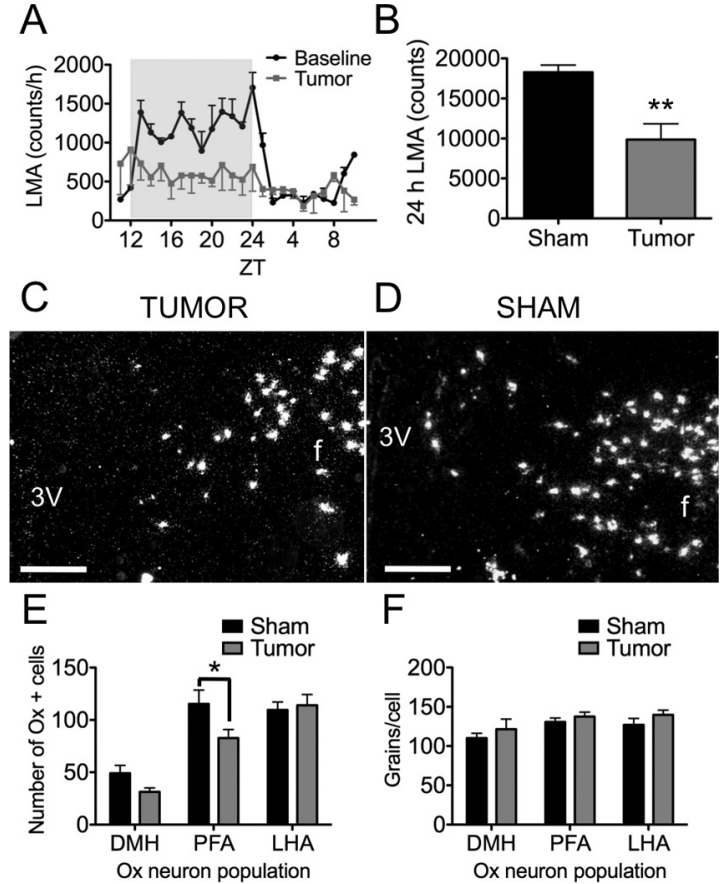

Figure 9. Tumor-induced inflammation inhibits home-cage LMA and reduces $0 x$ mRNA expression in the perifornical hypothalamus. $\boldsymbol{A}$, Hourly home-cage LMA in tumor-bearing rats $13 \mathrm{~d}$ after tumor implantation compared with baseline activity. $\boldsymbol{B}$, Twenty-four hour home-cage LMA in tumor-bearing rats compared with sham-operated, pair-fed controls during final day before being killed. C, D, Representative dark-field photomicrographs of in situ hybridization showing Ox mRNA expression (silver clusters) in tumor-bearing $(\boldsymbol{C})$ and sham-operated $(\boldsymbol{D})$ rats. $\boldsymbol{E}$, Quantification of the number of Ox mRNA-expressing cells in DMH, PFA, and LHA Ox neuron fields. $\boldsymbol{F}, 0 \times$ mRNA expression, represented as silver grains per cell, in each $0 x$ neuron population from tumor-bearing and sham-operated rats. Data are expressed as mean \pm SEM. ${ }^{*} p<0.05$. Scale bars, $200 \mu \mathrm{m}$. 3V, Third ventricle; f, fornix.

controls (Fig. 9B). In situ hybridization showed a significant decrease in the number of $O x$-expressing cells in tumor-bearing animals, specifically in the PFA Ox neuron distribution, but not in the DMH or LHA. No difference in the number of grains per cell was observed (Fig. 9C-F). These data indicate that suppression of Ox signaling may play a role in chronic disease as well, and they support the anatomic localization of inflammation-sensitive Ox neurons to the perifornical hypothalamus.

\section{Discussion}

Despite the ubiquitous suppression of physical activity and arousal in response to illness, the neural mediators of this response are unknown. We now demonstrate that inflammationinduced lethargy is mediated by suppression of normal Ox signaling. We show that crepuscular and FR-associated increases in Ox neuron activity and OxA release are suppressed by inflammatory challenge. Despite robust movement suppression, intracerebroventricular OxA replacement restored LMA in LPS-treated rats in both circadian and FR conditions of increased locomotion. This effect is not due to a nonspecific effect of pharmacological OxA administration, as the same dose of intracerebroventricular OxA did not increase LMA in veh-treated rats. It is unlikely that the suppression of Ox neuron activity is mediated by direct inflammatory or melanocortin signaling, but we show here evidence that Ntsexpressing GABAergic interneurons may play a key role in mediating Ox neuron inhibition.

Previous studies demonstrate that the medial (DMH/PFA) and lateral (LHA) Ox neuron populations exhibit distinct effects 
on behavior (Harris and Aston-Jones, 2006). Our cFos IR data support an anatomically based functional dichotomy for Ox neurons, as we observed increases in cFos IR in DMH and PFA, but not LHA, Ox neurons during both vespertine and food anticipatory peaks in LMA. We also observed a specific suppression of cFos IR in PFA Ox neurons, more than DMH, in response to LPS or central IL-1 $\beta$. This finding separates the medial arousalassociated $\mathrm{Ox}$ neuron population into inflammation-sensitive (PFA) and inflammation-insensitive (DMH) populations, and indicates that the activity of the PFA Ox neuron population is necessary for normal LMA responses to both circadian and noncircadian cues. It is important to note that our division of the $\mathrm{Ox}$ neuron distribution into these three anatomic zones is artificial. While the majority of inflammation-sensitive Ox neurons lie in the perifornical hypothalamus, our anatomic zones only approximate the actual division between inflammation-sensitive and -insensitive Ox neurons. Tract tracing has identified differences in innervation between medial (DMH/PFA) and lateral (LHA) Ox neurons that are consistent with previously reported roles for medial Ox neurons in mediating arousal, and for lateral Ox neurons in influencing reward and feeding (Yoshida et al., 2006). Similar examination of afferents to and projections from $\mathrm{DMH}$ and PFA subpopulations may define the circuits underlying arousal modulation and inflammation sensitivity.

Initially, we hypothesized that inflammatory cytokines inhibit Ox neurons by directly binding to these neurons. We found no evidence for the expression of cytokine receptors or the expression of NF- $\kappa$ B response genes following LPS treatment in $\mathrm{Ox}$ neurons. Previous reports describe a prominent role for PG signaling in pyresis (Engblom et al., 2003), anorexia (Lugarini et al., 2002), cFos induction (Dallaporta et al., 2007), and hypothalamopituitary-adrenal activation (Serrats et al., 2010). In accordance with Serrats et al. (2010), we found no effect of COX inhibition on LMA, indicating that LPS-induced lethargy is PG independent. However, we demonstrated that central IL- $1 \beta$ is sufficient, but not necessary, to suppress LMA and Ox neuron activity. Blocking nerve conduction through the dorsal vagal complex (DVC) prevents intraperitoneal LPS-induced social withdrawal and cFos IR in multiple nuclei (Marvel et al., 2004), identifying the brainstem as a crucial mediator of sickness behavior. Given that the DVC and central IL- $1 \beta$ can each independently mediate lethargy, we postulate that a population of inflammation-sensitive neurons that receive afferent input from the DVC integrates these two inflammatory signals and relays this signal to Ox neurons.

Recently, Leinninger et al. (2011) reported that leptin activates GABAergic Nts neurons in the LHA, which then inhibit $\mathrm{Ox}$ neuron activity. That LHA Nts neurons can respond to leptin indicates that, like arcuate nucleus POMC neurons, these neurons may be cytokine sensitive (Scarlett et al., 2007; Grossberg et al., 2010). The LPS-induced decrease in cFos IR in Ox neurons was associated with an increase in cFos IR in LHA Nts neurons, indicating that these interneurons play a common role in the allostatic suppression of LMA by both overnutrition and inflammation. The relationship between increased perifornical Nts neuron activation and decreased $\mathrm{Ox}$ neuron activation may not be causative. Furthermore, Nts neurons may inhibit Ox neurons via release of GABA, as with the leptin-responsive neurons. Alternatively the peptide neurotransmitter neurotensin may mediate this effect. Modulation of Ox neuron activity by LPS and leptin both alter the behavioral response to amphetamine (Fishkin and Winslow, 1997; Nakamura et al., 2000; Leinninger et al., 2011). This suggests exploitation of similar circuitry and supports a role for VTA dopamine signaling in mediating the LMA effects of LPS.
However, the effects of leptin and LPS are not completely congruent. In contrast to leptin, LPS does not acutely induce $O x$ mRNA expression. This may be explained by recruitment of unique, but overlapping Ox-regulating pathways by leptin and LPS. Further anatomic and functional studies are needed to elucidate the role of LHA Nts neurons in mediating LPS-induced suppression of Ox neurons.

Restoration of LMA in LPS-treated rats by intracerebroventricular OxA did not influence food intake, despite the well documented orexigenic properties of OxA. After intracerebroventricular injection, LPS/OxA-treated animals exhibit normal home-cage exploratory behavior, including investigation of their food hopper, but, unlike veh-treated rats, these animals seldom consume food. Therefore, the increase in LMA induced by OxA replacement was not simply an increase in feeding behavior, but rather represented a more active animal in lieu of depressed feeding. We previously reported that inflammation induces anorexia by increasing central melanocortin signaling, and that melanocortin antagonism restores feeding (Marks et al., 2001). We found no evidence that $\mathrm{Ox}$ neurons receive direct input from melanocortinergic neurons, though we observed MC4R expression in non-Ox neurons throughout the LHA. Melanocortins may, via MC4R, regulate the activity of LHA neurons that influence the Ox system, such as Nts neurons. Specific activation of AgRP neurons using designer receptors exclusively activated by designer drugs potently induces foraging behavior in the absence of food (Krashes et al., 2011). However, AgRP treatment failed to restore LMA in LPS-treated rats suggesting that either an alternative neurotransmitter released by AgRP neurons (e.g., NPY, GABA) coordinates feeding and LMA, or that nonsynaptically delivered AgRP acts ectopically to suppress LMA. Thus, in the setting of increased melanocortin tone following LPS administration, OxA provides an insufficient orexigenic stimulus to induce food intake. Conversely, blockade of MC4R has no effect on Oxdependent suppression of LMA. This marks the first time that these two features of sickness behavior have been mechanistically separated.

Though the present work focuses primarily on mechanisms of acute illness-induced lethargy, our TB rat studies suggest that $\mathrm{Ox}$ plays a role in the lethargy of chronic disease, as well. TB rats exhibited a decrease in the number of PFA Ox mRNA-expressing neurons, indicating either specific degeneration of these neurons or transcriptional repression of $\mathrm{Ox}$ synthesis in these cells. Either phenomenon, if responsible for cancer-associated lethargy, should be sensitive to Ox replacement. That the same neurons appear to be affected by both acute and chronic inflammatory insult indicates a similar mechanism underlies both phenomena. The effective restoration of LMA throughout the dark phase by subchronic OxA infusion in LPS-treated rats demonstrates that Ox replacement is a viable therapeutic avenue for sicknessinduced lethargy. Although allostatic suppression of LMA and food intake by inflammation is an important, and reversible, part of the response to acute infection, chronic dysregulation of metabolism leads to wasting, debilitation, and death. We propose that $\mathrm{Ox}$ agonists would be useful in chronically ill patients to improve quality of life and independent living.

\section{References}

Arruda AP, Milanski M, Romanatto T, Solon C, Coope A, Alberici LC, Festuccia WT, Hirabara SM, Ropelle E, Curi R, Carvalheira JB, Vercesi AE, Velloso LA (2010) Hypothalamic actions of tumor necrosis factor alpha provide the thermogenic core for the wastage syndrome in cachexia. Endocrinology 151:683-694.

Banks AS, Davis SM, Bates SH, Myers MG Jr (2000) Activation of down- 
stream signals by the long form of the leptin receptor. J Biol Chem 275:14563-14572.

Becskei C, Riediger T, Hernádfalvy N, Arsenijevic D, Lutz TA, Langhans W (2008) Inhibitory effects of lipopolysaccharide on hypothalamic nuclei implicated in the control of food intake. Brain Behav Immun 22:56-64.

Chemelli RM, Willie JT, Sinton CM, Elmquist JK, Scammell T, Lee C, Richardson JA, Williams SC, Xiong Y, Kisanuki Y, Fitch TE, Nakazato M, Hammer RE, Saper CB, Yanagisawa M (1999) Narcolepsy in orexin knockout mice: molecular genetics of sleep regulation. Cell 98:437-451.

Crestani F, Seguy F, Dantzer R (1991) Behavioural effects of peripherally injected interleukin-1: role of prostaglandins. Brain Res 542:330-335.

Cunningham MJ, Scarlett JM, Steiner RA (2002) Cloning and distribution of galanin-like peptide mRNA in the hypothalamus and pituitary of the macaque. Endocrinology 143:755-763.

Dallaporta M, Pecchi E, Jacques C, Berenbaum F, Jean A, Thirion S, Troadec JD (2007) c-Fos immunoreactivity induced by intraperitoneal LPS administration is reduced in the brain of mice lacking the microsomal prostaglandin E synthase-1 (mPGES-1). Brain Behav Immun 21:1109-1121.

Dantzer R (2001) Cytokine-induced sickness behavior: mechanisms and implications. Ann N Y Acad Sci 933:222-234.

Desarnaud F, Murillo-Rodriguez E, Lin L, Xu M, Gerashchenko D, Shiromani SN, Nishino S, Mignot E, Shiromani PJ (2004) The diurnal rhythm of hypocretin in young and old F344 rats. Sleep 27:851-856.

Engblom D, Saha S, Engström L, Westman M, Audoly LP, Jakobsson PJ, Blomqvist A (2003) Microsomal prostaglandin E synthase-1 is the central switch during immune-induced pyresis. Nat Neurosci 6:1137-1138.

Estabrooke IV, McCarthy MT, Ko E, Chou TC, Chemelli RM, Yanagisawa M, Saper CB, Scammell TE (2001) Fos expression in orexin neurons varies with behavioral state. J Neurosci 21:1656-1662.

Fishkin RJ, Winslow JT (1997) Endotoxin-induced reduction of social investigation by mice: interaction with amphetamine and anti-inflammatory drugs. Psychopharmacology (Berl) 132:335-341.

Gaykema RP, Goehler LE (2009) Lipopolysaccharide challenge-induced suppression of Fos in hypothalamic orexin neurons: their potential role in sickness behavior. Brain Behav Immun 23:926-930.

Georgescu D, Zachariou V, Barrot M, Mieda M, Willie JT, Eisch AJ, Yanagisawa M, Nestler EJ, DiLeone RJ (2003) Involvement of the lateral hypothalamic peptide orexin in morphine dependence and withdrawal. J Neurosci 23:3106-3111.

Gordon CJ, Heath JE (1980) Effects of prostaglandin E2 on the activity of thermosensitive and insensitive single units in the preoptic/anterior hypothalamus of unanesthetized rabbits. Brain Res 183:113-121.

Grossberg AJ, Scarlett JM, Zhu X, Bowe DD, Batra AK, Braun TP, Marks DL (2010) Arcuate nucleus proopiomelanocortin neurons mediate the acute anorectic actions of leukemia inhibitory factor via gp130. Endocrinology 151:606-616.

Hagan JJ, Leslie RA, Patel S, Evans ML, Wattam TA, Holmes S, Benham CD, Taylor SG, Routledge C, Hemmati P, Munton RP, Ashmeade TE, Shah AS, Hatcher JP, Hatcher PD, Jones DN, Smith MI, Piper DC, Hunter AJ, Porter RA, et al (1999) Orexin A activates locus ceruleuscell firing and increases arousal in the rat. Proc Natl Acad Sci U S A 96:10911-10916.

Harris GC, Aston-Jones G (2006) Arousal and reward: a dichotomy in orexin function. Trends Neurosci 29:571-577.

Haynes AC, Jackson B, Overend P, Buckingham RE, Wilson S, Tadayyon M, Arch JR (1999) Effects of single and chronic intracerebroventricular administration of the orexins on feeding in the rat. Peptides 20:1099-1105.

Krashes MJ, Koda S, Ye C, Rogan SC, Adams AC, Cusher DS, Maratos-Flier E, Roth BL, Lowell BB (2011) Rapid, reversible activation of AgRP neurons drives feeding behavior in mice. J Clin Invest 121:1424-1428.

Leinninger GM, Opland DM, Jo Y-H, Faouzi M, Gong Y, Christensen L, Cappellucci L, Pothos E, Yang H, Becker JB, Thompson RC, Seasholtz AF, Gnegy ME, Myers MG (2011) Lateral hypothalamic leptin receptor neu- rons containing neurotensin regulate orexin neurons, energy balance and the mesolimbic dopamine system. Cell Metab, in press.

Li Y, van den Pol AN (2008) Mu-opioid receptor-mediated depression of the hypothalamic hypocretin/orexin arousal system. J Neurosci 28:2814-2819.

Lord GM, Matarese G, Howard JK, Baker RJ, Bloom SR, Lechler RI (1998) Leptin modulates the T-cell immune response and reverses starvationinduced immunosuppression. Nature 394:897-901.

Lugarini F, Hrupka BJ, Schwartz GJ, Plata-Salaman CR, Langhans W (2002) A role for cyclooxygenase-2 in lipopolysaccharide-induced anorexia in rats. Am J Physiol Regul Integr Comp Physiol 283:R862-R868.

Marks DL, Ling N, Cone RD (2001) Role of the central melanocortin system in cachexia. Cancer Res 61:1432-1438.

Martínez GS, Smale L, Nunez AA (2002) Diurnal and nocturnal rodents show rhythms in orexinergic neurons. Brain Res 955:1-7.

Marvel FA, Chen CC, Badr N, Gaykema RP, Goehler LE (2004) Reversible inactivation of the dorsal vagal complex blocks lipopolysaccharideinduced social withdrawal and c-Fos expression in central autonomic nuclei. Brain Behav Immun 18:123-134.

Mieda M, Williams SC, Sinton CM, Richardson JA, Sakurai T, Yanagisawa M (2004) Orexin neurons function in an efferent pathway of a foodentrainable circadian oscillator in eliciting food-anticipatory activity and wakefulness. J Neurosci 24:10493-10501.

Nakamura T, Uramura K, Nambu T, Yada T, Goto K, Yanagisawa M, Sakurai T (2000) Orexin-induced hyperlocomotion and stereotypy are mediated by the dopaminergic system. Brain Res 873:181-187.

Paxinos G, Watson C (1998) The rat brain in stereotaxic coordinates, 4 Ed. New York: Academic.

Plata-Salamán CR, Oomura Y, Kai Y (1988) Tumor necrosis factor and interleukin-1 beta: suppression of food intake by direct action in the central nervous system. Brain Res 448:106-114.

Ryan JL, Carroll JK, Ryan EP, Mustian KM, Fiscella K, Morrow GR (2007) Mechanisms of cancer-related fatigue. Oncologist 12 [Suppl 1]:22-34.

Sakurai T (2007) The neural circuit of orexin (hypocretin): maintaining sleep and wakefulness. Nat Rev Neurosci 8:171-181.

Scarlett JM, Jobst EE, Enriori PJ, Bowe DD, Batra AK, Grant WF, Cowley MA, Marks DL (2007) Regulation of central melanocortin signaling by interleukin-1 beta. Endocrinology 148:4217-4225.

Scarlett JM, Zhu X, Enriori PJ, Bowe DD, Batra AK, Levasseur PR, Grant WF, Meguid MM, Cowley MA, Marks DL (2008) Regulation of agouti-related protein messenger ribonucleic acid transcription and peptide secretion by acute and chronic inflammation. Endocrinology 149:4837-4845.

Serrats J, Schiltz JC, García-Bueno B, van Rooijen N, Reyes TM, Sawchenko PE (2010) Dual roles for perivascular macrophages in immune-to-brain signaling. Neuron 65:94-106.

Smith BK, Conn CA, Kluger MJ (1993) Experimental cachexia: effects of MCA sarcoma in the Fischer rat. Am J Physiol 265:R376-R384.

Trivedi P, Yu H, MacNeil DJ, Van der Ploeg LH, Guan XM (1998) Distribution of orexin receptor mRNA in the rat brain. FEBS Lett 438:71-75.

Wakamatsu H, Yoshinobu Y, Aida R, Moriya T, Akiyama M, Shibata S (2001) Restricted-feeding-induced anticipatory activity rhythm is associated with a phase-shift of the expression of mPer 1 and mPer2 mRNA in the cerebral cortex and hippocampus but not in the suprachiasmatic nucleus of mice. Eur J Neurosci 13:1190-1196.

Yamanaka A, Beuckmann CT, Willie JT, Hara J, Tsujino N, Mieda M, Tominaga M, Yagami K, Sugiyama F, Goto K, Yanagisawa M, Sakurai T (2003) Hypothalamic orexin neurons regulate arousal according to energy balance in mice. Neuron 38:701-713.

Yoshida K, McCormack S, España RA, Crocker A, Scammell TE (2006) Afferents to the orexin neurons of the rat brain. J Comp Neurol 494:845-861.

Zhang F, Basinski MB, Beals JM, Briggs SL, Churgay LM, Clawson DK, DiMarchi RD, Furman TC, Hale JE, Hsiung HM, Schoner BE, Smith DP, Zhang XY, Wery JP, Schevitz RW (1997) Crystal structure of the obese protein leptin E-100. Nature 387:206-209. 